\title{
ANALIZA STATECZNOŚCI STATYCZNEJ SAMOLOTU ZESPOLONEGO DO TURYSTYKI KOSMICZNEJ
}

\begin{abstract}
W pracy przedstawiono analizę stateczności samolotu zespolonego do turystki kosmicznej. Koncepcja tego samolotu zakłada, że będzie się on składał z samolotu matki i rakietoplanu. Profil misji układu będzie miał następujący przebieg: rakietoplan zostaje wyniesiony przez samolot matkę, obiekty rozdzielają się, samolot matka wraca na lotnisko. W tym samym czasie rakietoplan wykonuje lot suborbitalny, podczas którego przekracza granicę atmosfery ziemskiej i kosmosu. Każdy kto przekroczy wspomnianą granicę jest uznawany za astronautę. Praca zawiera wyniki obliczeń stateczności statycznej oraz równowagi dla wspomnianego samolotu zespolonego dla dwóch typów konfiguracji. W pierwszym przypadku założono, że rakietoplan jest wykorzystywany jako usterzenie znajdujące się za płatem samolotu matki (klasyczna konfiguracja usterzenia). Natomiast w drugim przypadku rozważano układ kaczki, gdzie rakietoplan znajdował się przed płatem samolotu matki. Praca prezentuje wyniki tylko dla etapu misji tuż przed procesem separacji obiektów. Obliczenia stateczności i równowagi zostały przeprowadzone za pomocą programu AVL.
\end{abstract}

Słowa kluczowe: samolot zespolony, turystyka kosmiczna, stateczność statyczna

\section{Wprowadzenie}

Turystyka kosmiczna stanowi ważną i przyszłościową gałąź sektora kosmicznego. Koszt podróży na Międzynarodową Stację Kosmiczną to około 20-30 mld USD [1]. Dodatkowym wymaganiem jest odbycie wielotygodniowego treningu. Istnieje spora grupa zainteresowanych tego rodzaju podróżami, lecz nie wystarczająco zamożna, aby pozwolić sobie na taki wydatek. Konkurs Ansari X-Prize [2] zwrócił uwagę na inną koncepcję - lot suborbitalny. Idea takiego lotu zakłada przekroczenie umownej granicy między atmosferą ziemską a przestrzenią kosmiczną, która znajduje się na wysokości $100 \mathrm{~km}$ nad poziomem morza. Każda osoba przekraczająca ową granicę jest uznawana za astronautę. W przypadku lotu suborbitalnego pojazd nie wchodzi na orbitę, lecz przekracza wspomnianą granicę, dlatego koszt takiej podróży jest znacznie niższy. Konkurs

\footnotetext{
${ }^{1}$ Autor do korespondencji/corresponding author: Agnieszka Kwiek, Politechnika Warszawska, ul. Nowowiejska 24, Warszawa, tel. (22) 2347445, e-mail: akwiek@ meil.pw.edu.pl
} 
Ansari X-Prize został ogłoszony w 1996 r. przez Fundację X PRIZE. Zgodnie z jego zasadami należało zbudować pojazd wielokrotnego użytku dla trzech osób, zdolny wykonać dwa loty w przeciągu dwóch tygodni, podczas których zostałaby przekroczona wysokość $100 \mathrm{~km}$ nad poziomem morza. W konkursie mogły wziąć udział tylko firmy prywatne. Zwyciężył zespół Scaled Composites z projektem Tier One [3], który składał się z dwóch obiektów: samolotu matki (White Knight) oraz rakietoplanu (Space Ship One). Na pokładzie rakietoplanu znajdował się pilot, pasażerowie zaś zostali zastąpieni przez balast. Zwycięska drużyna otrzymała nagrodę w wysokości $10 \mathrm{mln}$ USD, którą przeznaczyła na rozwój projektu komercyjnych lotów turystycznych.

Koncepcja wykorzystania samolotu jako nosiciela dla drugiego samolotu nie jest nową ideą. Przed drugą Wojną Światową w Związku Radzieckim rozwijano projekt Zveno, który zakładał wykorzystanie bombowca jako nosiciela dla samolotów myśliwskich. Przykładem cywilnego zastosowania samolotów zespolonych jest S.20 Mercury \& S.21 Maia, które były wykorzystywane do transportu poczty. Ponadto NASA wykorzystała samolot Boeing B-52 Stratofortress jako nosiciel dla samolotu eksperymentalnego X-15. Dotychczasowe konstrukcje charakteryzowały się znacząco większą masą samolotu nosiciela w stosunku do samolotu wynoszonego. W przypadku projektu Tier One masa obu obiektów jest zbliżona. Obecnie kilka prywatnych firm pracuje nad pierwszym komercyjnym pojazdem przeznaczonym do turystyki kosmicznej. Dodatkowo rozważa się wykorzystanie pojazdów do lotów suborbitalnych do wynoszenia mikrosatelitów. W takim przypadku można wyposażyć pojazd w dodatkowy stopień, który umieści ładunek użyteczny na orbicie. Dodatkowo pojazdy takie można wykorzystać jako platformy do testowania nowych technologii kosmicznych i podniesienia poziomu gotowości technologicznej (Technology Readiness Level, TRL). Ponadto rozważa się w dalekiej przyszłości loty suborbitalne jako szybki sposób podróży z punktu do punktu.

\section{Koncepcja samolotu zespolonego}

Ze względu na zapotrzebowanie rynku na pojazd do turystki na Wydziale Mechanicznym Energetyki i Lotnictwa Politechniki Warszawskiej w Zakładzie Samolotów i Śmigłowców powstał pomysł projektu samolotu zespolonego [4-6]. Koncepcja została zainspirowana przez Space Ship One \& White Knight, ale wyróżnia się kilkoma istotnymi cechami konstrukcyjnymi. Po pierwsze zakłada, że oba samoloty są zaprojektowane w układzie bezogonowym, a po połączeniu płat rakietoplanu będzie stanowić usterzenie całego układu (rys. 1.). Dodatkowo tuż przed procesem separacji środek ciężkości rakietoplanu nie znajduje się pod środkiem ciężkości nosiciela. Ponadto rakietoplan jest wyposażony w skrzydło pasmowe, które na dużych kątach natarcia generuje dodatkowe wiry zwiększające w efekcie siłę nośną. Zjawisko to jest nazywane wyporem wirowym [7] i jest głównie stosowane przez samoloty bojowe do zwiększenia manewrowości [8]. 
Wykorzystanie wyporu wirowego jest planowane podczas lotu powrotnego w celu wyhamowania rakietoplanu. Profil misji samolotu zespolonego (rys. 2.) zakłada następujące etapy:

1. Start samolotu zespolonego z lotniska w konwencjonalny sposób, tak jak w przypadku samolotów pasażerskich.

2. Wznoszenie na około $15 \mathrm{~km}$ nad poziomem morza.

3. Separacja obiektów.

4. Powrót samolotu matki na lotnisko, włączenie w tym samym czasie hybrydowego silnika rakietowego $\mathrm{w}$ rakietoplanie. Rakietoplan rozpoczyna wznoszenie.

5. Wyłączenie silnika na około $60 \mathrm{~km}$ nad poziomem morza. Przejście rakietoplanu w fazę lotu balistycznego, podczas którego przekroczy granicę kosmosu.

6. Lot powrotny jako lot ślizgowy z wykorzystaniem zjawiska wyporu wirowego.

W pracy będzie rozważany tylko etap misji tuż przed procesem separacji obiektów, pozostałe fazy nie będą analizowane.

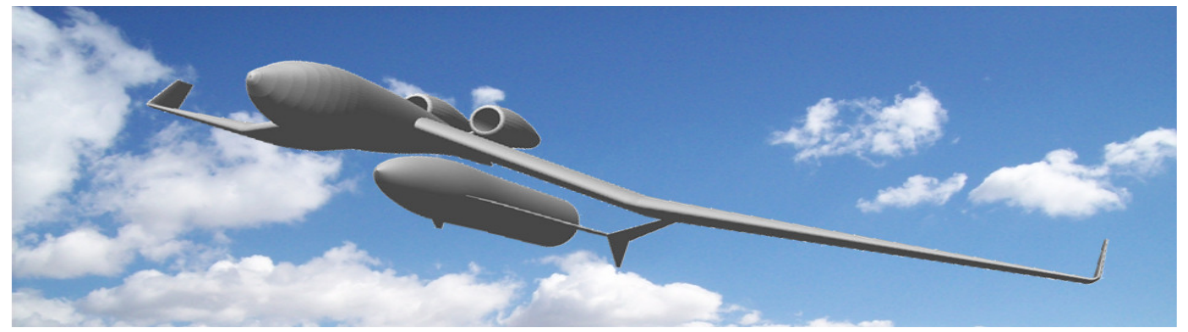

Rys. 1. Samolot zespolony do turystyki kosmicznej

Fig. 1. Modular airplane for space tourism

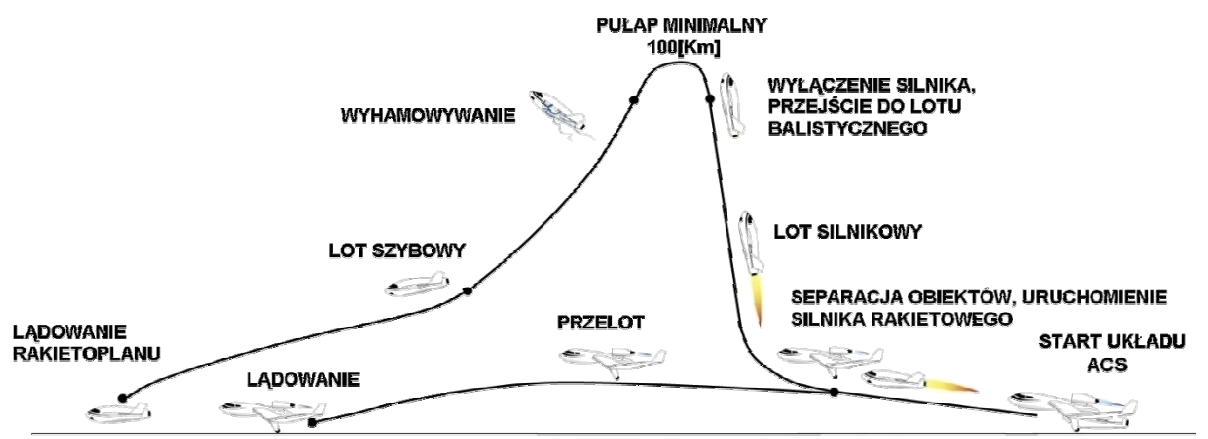

Rys. 2. Profil misji samolotu modułowego

Fig. 2. Mission profile of modular airplane 


\section{Obliczenia numeryczne}

Obliczenia numeryczne przeprowadzono za pomocą programu AVL [9] wykorzystującego metodę siatki wirowej (Vortex Lattice Method). Program ten nie uwzględnia oderwania, można więc rozważać tylko część linową charakterystyk. Dodatkowo otrzymane wyniki współczynników oporu uwzględniają tylko opór indukowany. Oznacza to, że wartość współczynnika siły oporu jest znaczenie zaniżona. Głównym celem analizy jest przeprowadzenie wstępnych obliczeń stateczności statycznej i równowagi, uznano więc, że na tym etapie projektowania program AVL będzie wystarczającym narzędziem. W celu określenia, w jakim zakresie charakterystyka jest liniowa wykorzystano program MGAERO [10]. Oprogramowanie to jest oparte na równaniach Eulera i wykorzystuje metodę wielosiatkową [11]. Rozważano dwa główne typy konfiguracji samolotu zespolonego. Pierwszy zakładał, że rakietoplan znajduje się z tyłu, tak jak w klasycznym samolocie. Natomiast drugi, że samolot zespolony jest w układzie kaczki. Dla każdego z tych typów rozważano różne wzajemne położenia obiektów. W modelu stworzonym na potrzeby obliczeń w programie AVL został uproszczony kadłub nosiciela i rakietoplanu, który został zamodelowany jako płaska płytka, modelu rakietoplanu nie wyposażono zaś w skrzydło pasmowe. Przykłady modeli numerycznych przedstawiają rys. 3. oraz 4.

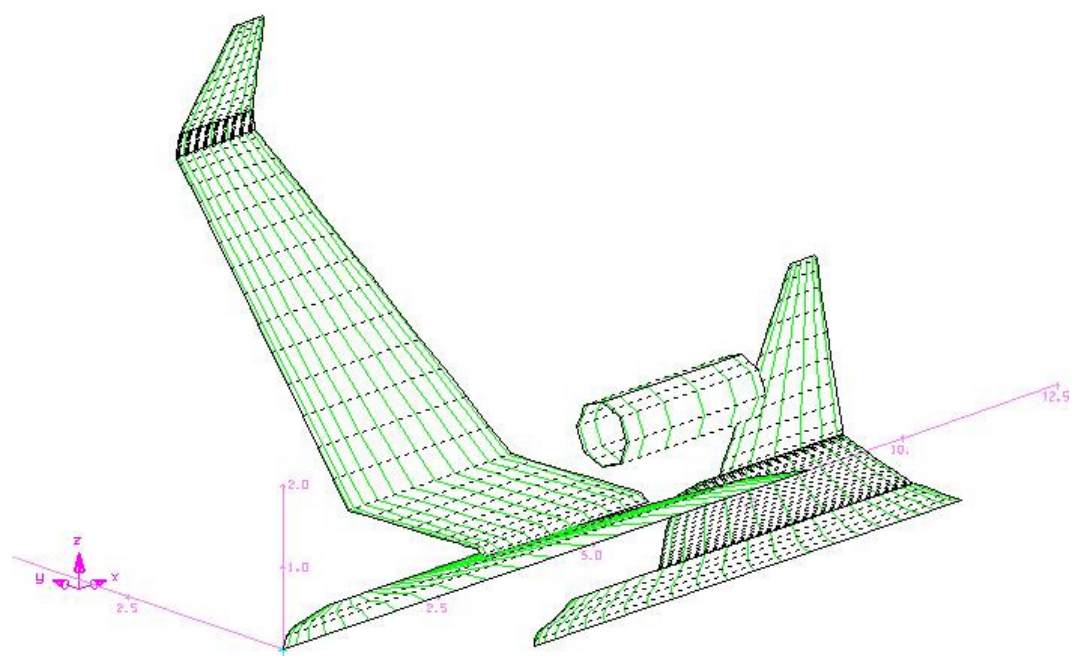

Rys. 3. Model numeryczny dla przypadku konfiguracji klasycznej

Fig. 3. Numerical model for classic tail configuration

Położenie rakietoplanu będzie definiowane za pomocą cechy objętościowej usterzenia poziomego, która jest opisana równaniem (1). Dodatkowym parametrem będzie odległość między 25\% średniej cięciwy aerodynamicznej samolotu 
matki a $25 \%$ średniej cięciwy aerodynamicznej rakietoplanu wyrażona w procentach średniej cięciwy aerodynamicznej samolotu matki:

$$
\frac{S_{H} \cdot l_{H}}{S_{W} \cdot S C A}=\kappa
$$

gdzie: $S_{H} \quad$ - powierzchnia usterzenia poziomego,

$S_{W}$ - powierzchnia płata,

$S C A$ - średnia cięciwa aerodynamiczna,

$l_{H}$ - ramię usterzenia poziomego (odległość między 25\% SCA płata a $25 \% S C A$ usterzenia),

$\kappa \quad-$ cecha objętościowa usterzenia poziomego.

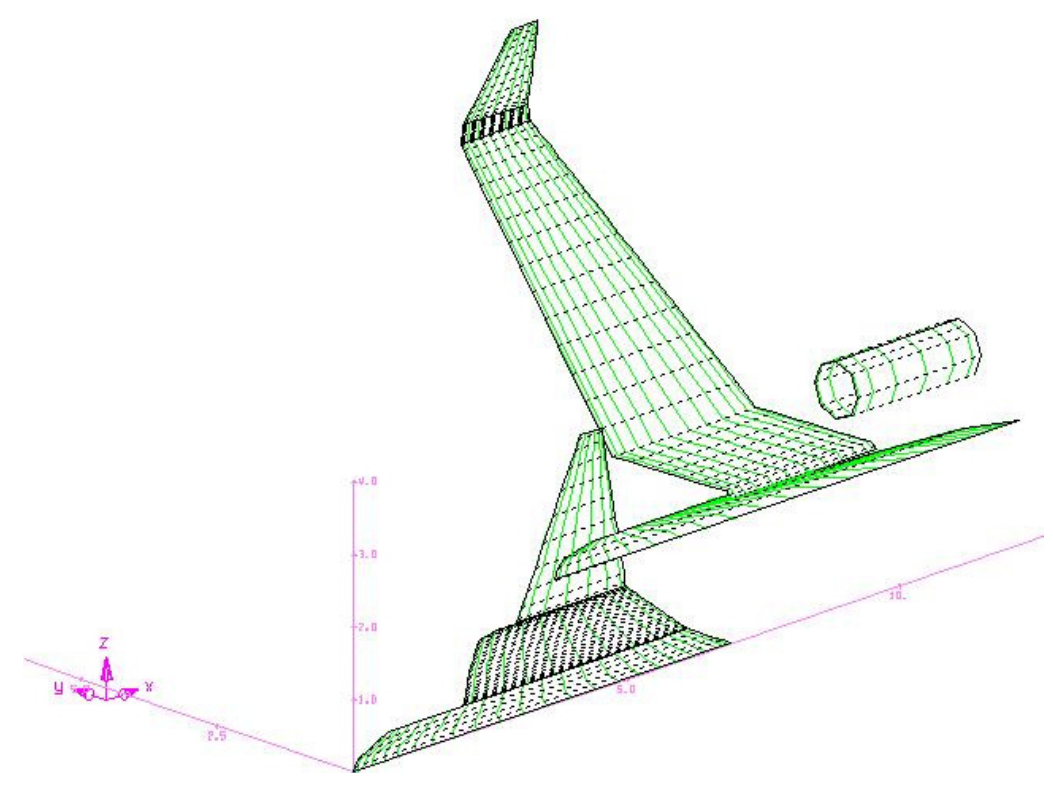

Rys. 4. Model numeryczny dla konfiguracji kaczki

Fig. 4. Numerical model for canard configuration

Wszystkie analizy zostały przeprowadzone dla środka ciężkości tuż przed procesem separacji, czyli dla przypadku, w którym samolot matka ma 60\% masy paliwa, a rakietoplan - masę startową. W zależności od wzajemnego położenia samolotów położenie wspólnego środka ciężkości było indywidualnie wyznaczane. Jako powierzchnię odniesienia założono powierzchnię płata samolotu matki. Wszystkie obliczenia zostały wykonane dla liczby Macha $M a=0.51$, która odpowiada wcześniej założonej prędkości przed procesem separacji. Geometria rakietoplanu (usterzenia) jest niezmienna podczas wszystkich analiz prezentowanych w niniejszej pracy. 


\section{Wyniki dotyczące stateczności układu}

Na podstawie wyników otrzymanych z programu MGAERO stwierdzono, że charakterystyka momentu jest liniowa do kąta natarcia 8 stopni (rys. 5.). W związku z tym do obliczeń w programie AVL przyjęto zakres kątów natarcia od -4 do 8 stopni. Ocenę stateczności statycznej dokonano za pomocą wykresu współczynnika momentu pochylającego w funkcji kąta natarcia. Zgodnie z konwencją przedstawioną w pracy [12] samolot jest stateczny, gdy jest spełniony warunek opisany równaniem:

$$
\frac{\mathrm{d} C m}{\mathrm{~d} \alpha}<0
$$

gdzie: $C m$ - współczynnik momentu pochylającego,

$\alpha$ - kąt natarcia.
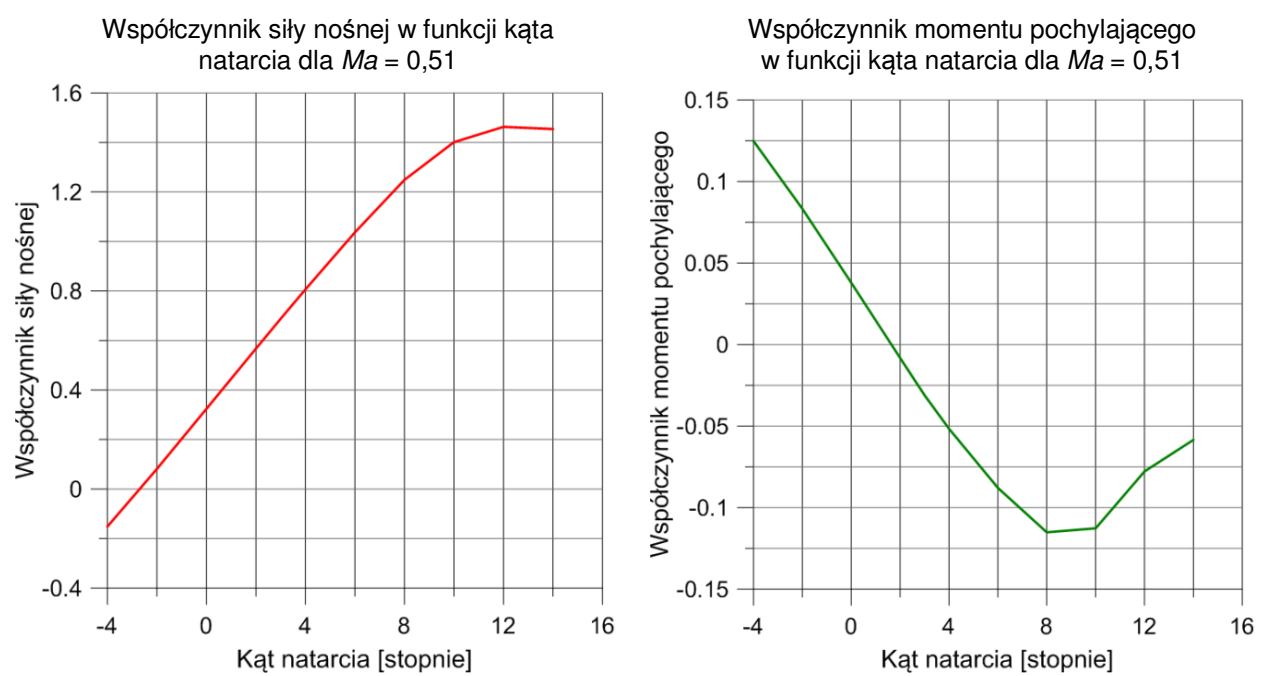

Rys. 5. Wykres współczynnika siły nośnej i momentu pochylającego w funkcji kąta natarcia, wyniki otrzymane za pomocą programu MGAERO

Fig. 5. Lift force and pitching moment coefficient versus angle of attack obtained by MGAERO software

Pierwsza grupa wyników obejmuje analizy dla klasycznego układu samolotów, gdzie usterzenie (rakietoplan) znajduje się z tyłu. Obliczenia stateczności przeprowadzono dla konfiguracji, gdy cecha objętościowa wynosi 0,376 . W takim przypadku wspomniana odległość między $25 \%$ średniej cięciwy aerodynamicznej samolotu matki a 25\% średniej cięciwy rakietoplanu wynosi $87 \%$ długości średniej cięciwy samolotu matki. Następnie przeprowadzono analizy dla kilku położeń rakietoplanu. Ostatecznie, na podstawie wyników z programu 
AVL stwierdzono, że cecha objętościowa powinna wynosić 0,298 , co odpowiada odległości równej $110 \%$ długości średniej cięciwy samolotu matki mierzonej między $25 \%$ średniej cięciwy aerodynamicznej samolotu matki a 25\% średniej cięciwy rakietoplanu. Dla tej konfiguracji jest spełniony warunek $\frac{\mathrm{d} C m}{\mathrm{~d} \alpha}<0$, co oznacza, że samolot jest stateczny statycznie w rozważanym zakresie kątów natarcia (rys. 6.). Drugą część stanowią wyniki dla modelu w układzie kaczki, gdzie rakietoplan znajduje się z przodu. Analizę wykonano dla cech objętościowych w zakresie od 0,82 do 0,84 , co odpowiada zakresowi odległości od 241 do $246 \%$ długości średniej cięciwy aerodynamicznej nosiciela. Warunek $\frac{\mathrm{d} C m}{\mathrm{~d} \alpha}<0$ jest również spełniony dla samolotu w układzie kaczki, czyli samolot jest także stateczny statycznie w rozważanym zakresie kątów natarcia (rys. 6.).

Rys. 6. Współczynnik momentu pochylającego w funkcji kąta natarcia dla samolotu w układzie klasycznym oraz kaczki, wyniki otrzymane za pomocą programu AVL

Fig. 6. Pitching moment coefficient versus angle of attack for classical and canard configurations obtained by AVL software

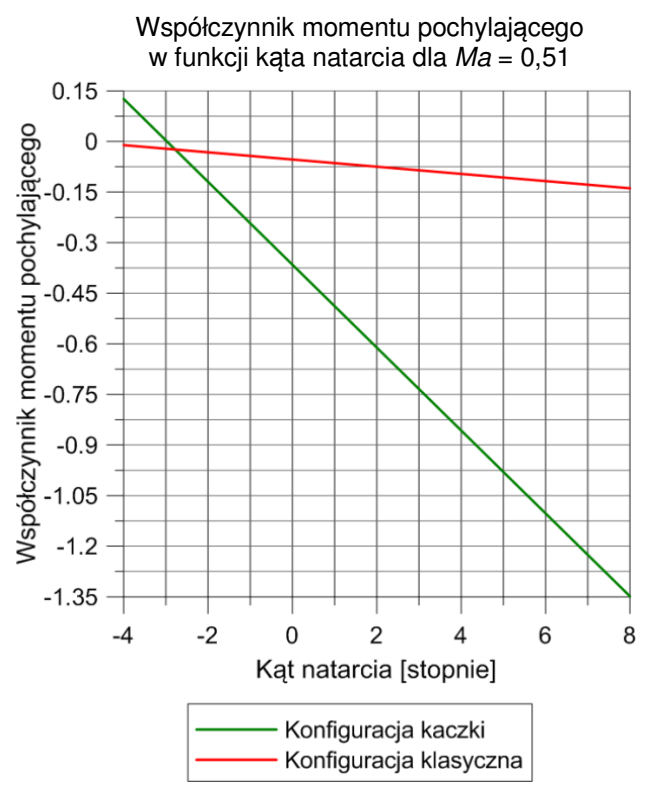

\section{Wyniki dotyczące równowagi układu}

Stan równowagi był zapewniany przez wychylenie dwusegmentowych sterolotek, które obejmowały $30 \%$ cięciwy głównego skrzydła rakietoplanu. Pierwszy etap obejmował wyznaczenie biegunowej równowagi dla wybranego położenia rakietoplanu względem samolotu matki dla przypadku usterzenia z tyłu. Założono, że kąt zaklinowania rakietoplanu wynosi zero. Otrzymane wyniki prezentuje rys. 7. Następnie sprawdzono, jakie jest wymagane wychylenie obu 
sterolotek w celu zapewnienia równowagi dla współczynnika siły nośnej odpowiadającego prędkości tuż przed separacją na wysokości $15 \mathrm{~km}$ nad poziomem morza. Wspomniane wychylenie wynosi -10 stopni. Następnie sprawdzono, jaki powinien być kąt zaklinowania rakietoplanu względem samolotu matki, aby w warunkach lotu tuż przed separacją zapewnić stan równowagi bez wychylenia powierzchni sterowych. Kąt ten powinien wynosić $-4,4$ stopnia. Dla samolotu zespolonego w konfiguracji z zaklinowanym rakietoplanem wykonano ponowne obliczenia równowagi. Otrzymane wyniki prezentuje rys. 8 .
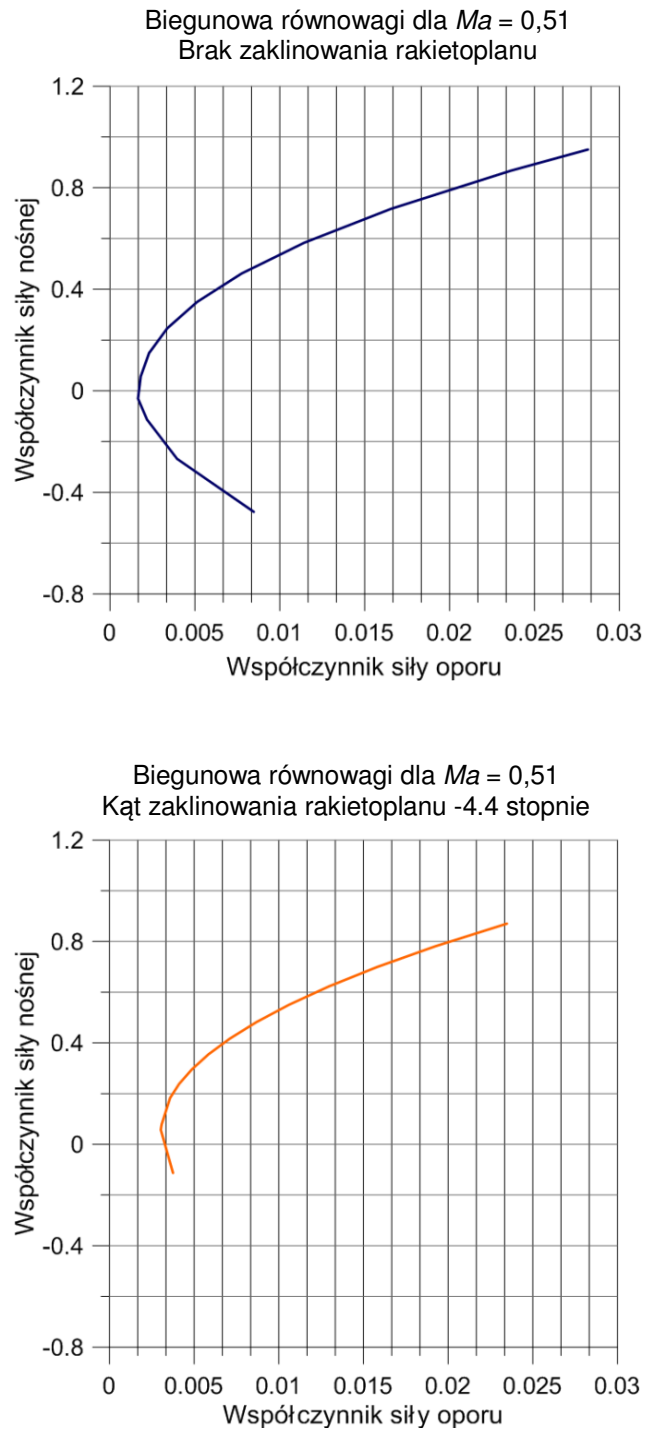

Rys. 7. Zależność współczynnika siły nośnej od współczynnika siły oporu w momencie separacji dla kąta zaklinowania rakietoplanu 0 stopni

Fig. 7. Lift force coefficient versus drag force coefficient for trim condition, rocket plane angle of incidence 0 degree

Rys. 8. Zależność współczynnika siły nośnej od współczynnika siły oporu w momencie separacji dla kąta zaklinowania rakietoplanu $-4,4$ stopni

Fig. 8. Lift force coefficient versus drag force coefficient for trim condition, rocket plane angle of incidence $-4,4$ degree 
Kolejnym etapem były obliczenia dla konfiguracji usterzenia z przodu. W tym przypadku jako powierzchnie sterowe wykorzystano sterolotki samolotu matki, które obejmowały $30 \%$ cięciwy. Nie udało się uzyskać stanu równowagi samolotu dla warunków lotu tuż przed separacją obiektów w zakresie kątów natarcia do 8 stopni.

\section{Wnioski końcowe}

Samolot w układzie kaczki jest statycznie stateczny, ale posiada bardzo duży współczynnik momentu pochylającego (patrz rys. 6.). Dodatkowo, powierzchnie sterowe w postaci sterolotek samolotu matki są niewystarczające, aby zapewnić stan równowagi dla warunków lotu tuż przed procesem separacji. Problemy te próbowano rozwiązać poprzez przesuwanie obiektu względem samolotu matki, niestety nie udało się osiągnąc satysfakcjonujących wyników. Samolot w konfiguracji klasycznej posiada wystarczająco duże powierzchnie sterowe, aby zapewnić stan równowagi dla warunków tuż przed procesem separacji. Dodatkowo cecha objętościowa usterzenia została zmieniona na 0,298 oraz wprowadzono zaklinowanie rakietoplanu względem nosiciela, tak aby w warunkach lotu tuż przed separacją można było uzyskać stan równowagi bez wychylenia powierzchni sterowych. Wspomniany kąt zaklinowania wynosi $-4,4$ stopnie. Kolejnym etapem badań będzie przeprowadzenie właściwej analizy stateczności za pomocą pakietu SDSA [13].

\section{Literatura}

[1] Space tourism market study orbital space travel \& destinations with suborbital space travel. Furton Corporation, October 2002.

[2] http://space.xprize.org/ansari-x-prize.

[3] Linehan D.: Space ship one. An Illustrated History, Zenith Press, 2008.

[4] Galiński C., Goetzendorf-Grabowski T., Mieszalski D., Stefanek Ł.: A concept of two-staged space plane for suborbital tourism. Prace Instytutu Lotnictwa, 191 (2007), 33-42.

[5] Stefanek Ł., Mieszalski D.: The two staged, suborbital, tourist space plane project: Aerodynamic influence analysis during second stage separation. Research and Education in Aircraft Design, Brno 2008.

[6] Figat M., Galiński C., Kwiek A.: Modlular airplane system. A Concept and Initial Investigation. ICAS 2012, Int. Congress, Brisbane, Australia 2012.

[7] Lamra J.E., Frink N.T.: Aerodynamic features of designed strake-wing configurations. J. Aircraft, 19 (1982), 639-642.

[8] Goraj Z.: Dynamika i aerodynamika samolotów manewrowych z elementami obliczeń. Wydaw. Naukowe Instytutu Lotnictwa, Warszawa 2001.

[9] http://web.mit.edu/drela/Public/web/avl/.

[10] MGAERO User's Manual version 3.1.4. 
[11] Mavriplis D.J.: Three-dimensional unstructured multigrid for the euler equations. J. Aircraft, 30 (1992), 1753-1761.

[12] Nelson R.C.: Flight stability and automatic control. McGraw-Hill, Singapur 1998.

[13] http://www.ceasiom.com/ceasiom-modules/sdsa.html.

Niniejsza praca jest wspótfinansowana przez Unię Europejska w ramach Europejskiego Funduszu Spotecznego poprzez realizacje projektu „Program rozwoju dydaktycznego Wydziatu Mechanicznego Energetyki i Lotnictwa Politechniki Warszawskiej”.

\title{
ANALYSIS OF STATIC STABILITY OF THE MODULAR AIRPLANE SYSTEM TO SPACE TOURISM
}

\begin{abstract}
The paper presents the study on static stability of a Modular Airplane System (MAS) to space tourism. The concept assumes that the modular airplane will be consisted of the mother plane and the rocket plane. A mission profile will contain following phases: the rocket plane will be lifted by the mother plane then vehicles will be separated. Next the carrier will return to the airfield. At the same time the rocket plane will perform suborbital flight, crossing the boundary between Earth atmosphere and outer space. Everyone who will cross this boundary will become an astronaut. The paper includes the results of static stability and trim condition for two types of the MAS configuration just before separation process. The first one assumes that the rocket plane is used as the MAS tail and is placed behind the mother plane's wing (classic configuration). The second one is canard configuration and the rocket plane is placed in front of the mother airplane's wing. The calculations of static stability and trim conditions were conducted by AVL software.
\end{abstract}

Keywords: modular airplane, space tourism, static stability

DOI: $10.7862 / \mathrm{rm} .2013 .42$

Otrzymano/received: $15.09 .2013 \mathrm{r}$.

Zaakceptowano/accepted: 22.11.2013 r. 